Original Research Article

\title{
Assessment of prescription pattern of cataract patients in the ophthalmology department at a tertiary health care institution
}

\author{
Karishma Adhikari*, Bezbaruah B. K.
}

Department of Pharmacology, Gauhati Medical College, Guwahati, Assam, India

Received: 21 December 2016

Revised: 26 December 2016

Accepted: 13 January 2017

*Correspondence to:

Dr. Karishma Adhikari,

Email:

karismaadhikari@gmail.com

Copyright: () the author(s), publisher and licensee Medip Academy. This is an openaccess article distributed under the terms of the Creative Commons Attribution NonCommercial License, which permits unrestricted noncommercial use, distribution, and reproduction in any medium, provided the original work is properly cited.

\begin{abstract}
Background: Evaluation of the current prescription pattern of cataract patients in the Ophthalmology Department to find out utilization of drugs per prescription that reflects possibilities of drug interaction and patient compliance and to suggest measures for rational prescriptions.

Methods: The study was carried out in the Ophthalmology Department at Gauhati Medical College and Hospital, Guwahati for a period of 6 months after obtaining permission from the Institutional Human Ethics Committee. This was a retrospective, observational hospital based study. The present study included patients of any age group and both the sexes (male/female) who were diagnosed as having cataract and who were prescribed different categories of drugs. A total of 156 prescriptions were collected, analysed and classified during the study period (both outdoor and indoor patients).

Results: Our study found that maximum numbers of patients were encountered in the age group of 45-65 years and around 48.4\% of cases for IOL implantation were having immature senile cataract. Topical eye drops are most commonly used account for $56.3 \%$ in preoperative cases. Overall 564 drugs were prescribed on discharge in 156 prescriptions; So on an average 3.6 drugs were prescribed per prescription. Overall antimicrobials $(51.80 \%)$ are most commonly prescribed group followed by anti-inflammatory (25.10\%), anxiolytic, steroid etc.

Conclusions: Our study showed a significant awareness to avoid polypharmacy by keeping average number of drugs per prescription as low as possible to avoid increased cost of the therapy, therapeutic failure, and adverse drug reactions and hence for better patient compliance.
\end{abstract}

Keywords: Antimicrobials, Cataract, IOL Implantation, Polypharmcy, Prescription pattern

\section{INTRODUCTION}

Development of opacity in the lens which is normally completely transparent is known as cataract. ${ }^{1}$ It is the most common cause of blindness worldwide. It can be congenital, developmental or acquired. A cataract can be unilateral or bilateral.

With normal aging process which is the commonest risk factor, nuclear lens protein undergoes aggregation and chemically modified to produce pigmentation and thus decreasing transparency. It ultimately leads to degenerative process causing opacification of lens fibres. Aging causes capsular, sub capsular, cortical, nuclear cataract. Other risk factors are trauma, Metabolic disorder (Diabetes), Intraocular disease (Uveitis).
Some of the symptoms of cataract are Glare (intolerance of bright light) - earliest visual disturbance, Uniocular Polyopia (doubling of objects), Frequent Prescription changes in eyeglasses, Coloured halos and Painless, Gradually progressive loss of vision. ${ }^{2}$

Cataract is detected through comprehensive eye examination that includes: Visual acuity testing, Slit lamp examination, distant direct ophthalmoscopic examination.

Surgery is the only effective treatment for cataract. As with any surgery, cataract surgery also possesses risks such as infection, bleeding, inflammation and double vision. With prompt medical attention by using various drugs like antimicrobials, steroids, mydriatics, this conditions can be prevented and treated. ${ }^{3-5}$ 
Such a large number of medications require control over prescribing especially when many consider it to be unnecessary, inappropriate and downright dangerous to prevent drug interactions and polypharmacy. ${ }^{6}$ Hence there is a need for a systematic review regarding the role of drugs like antimicrobials, corticosteroids and mydriatics in such a setting. ${ }^{7}$

Prescription is a legal written order containing drugs given by the physicians to the patients. Errors in prescription may be due to inadequate knowledge about the disease or the drug prescribed or ignorance. ${ }^{8-10}$ So, it should be scientifically legible, unambiguous, adequate and complete. It has been well accepted that inadequate and irrational prescriptions could lead to serious consequences like potential hazards for patients and unnecessary expenses. ${ }^{11}$

Recently an increased attention has been diverted to rational prescribing and study of drug prescribing patterns play a major role in this regard. ${ }^{12}$ These studies not only detect flaws in the therapy, but also help to find out solution to rectify the same.

So, the present study was undertaken to analyze and systematically review the role of various drugs administered to patients undergoing cataract surgery in a tertiary health care institution by evaluating the current prescription pattern of cataract patients in the Ophthalmology Department and also to find out utilization of drugs per prescription that can reflects possibilities of drug interaction and patient compliance and hence suggest some measures for rational prescriptions.

\section{METHODS}

The study was carried out in the Ophthalmology Department at Gauhati Medical College and Hospital, Guwahati for a period of 6 months $\left(10^{\text {th }}\right.$ Feb 2015 to $10^{\text {th }}$ Aug 2015) after getting the permission from the Institutional Human Ethics Committee vide letter no. $\mathrm{MC} / 2 / 2015 / 81$ and Head of the Department, Ophthalmology Department, Gauhati Medical College and Hospital, Guwahati.

This was a retrospective, observational hospital based study. We have not performed any activity on the patients but only data have been collected. The present study included patients of any age group and both the sexes (male/female) who were diagnosed as having cataract and who were prescribed different categories of drugs. Patients coming to the Ophthalmology Department who were not diagnosed as having cataract were excluded from this study.

A total of 156 prescriptions were collected, analysed and classified during the study period (both outdoor and indoor patients). The prescriptions were collected daily, right from the day of admission till the time of discharge of the patient and following parameters were observed.

\section{Data analysis}

The data obtained from the analysis of 156 prescriptions was further condensed and a master chart was prepared using MS-Excel. The data was subjected to statistical analysis.

The overall information generated was presented under the following headings:

1. Age wise distribution of cataract in patients undergoing surgery.

2. Sex wise distribution of cataract in patients undergoing surgery.

3. Distribution of patients according to the type of cataract involved.

4. Common condition associated with cataract

5. Formulation of drug most commonly prescribed

6. Drug use indicators like average number of drugs used per prescriptions, number of generics used.

7. List of all drugs employed in patients undergoing cataract surgery

8. Pre-operative drugs employed in patients undergoing surgery.

9. Post-operative drugs employed in patients after surgery.

10. Drugs prescribed on discharge in patients after surgery.

\section{RESULTS}

About 156 prescriptions were included in the study and analysed after matching the inclusion and exclusion criteria as mentioned earlier from 10-04-2015 to 10-072015 from Gauhati medical college and hospital. Out of the 156 prescriptions studied:

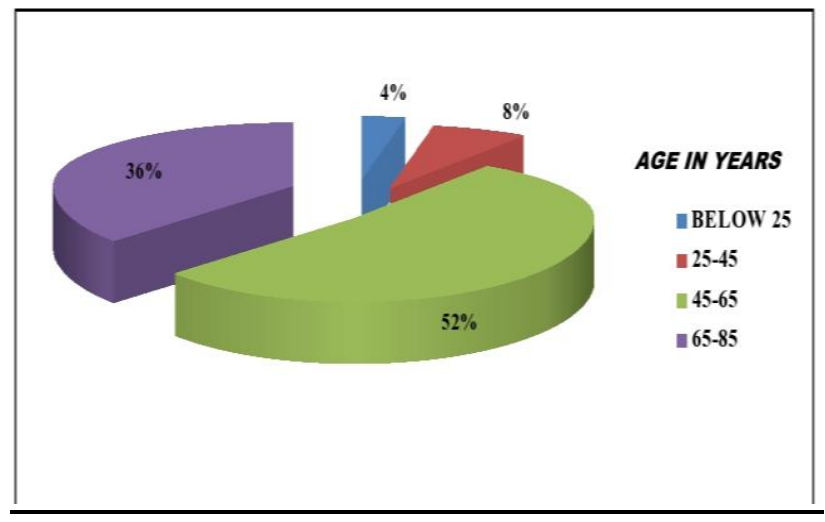

Figure 1: Age wise distribution of cataract patients shows maximum numbers of patients $(52 \%)$ were encountered in the age group of 45-65 years.

Maximum numbers of patients were encountered in the age group of 45-65 years (Figure 1). 
$56.4 \%$ were female and $43.6 \%$ were males having cataract (Figure 2).

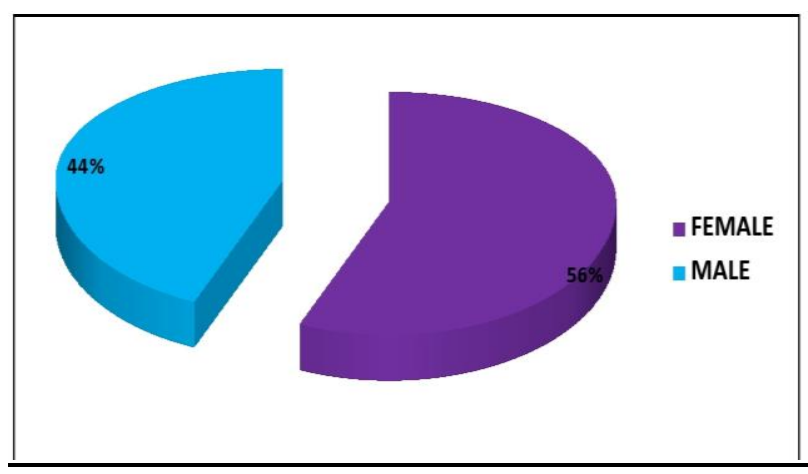

Figure 2: Gender wise distribution of cataract patients shows $56.4 \%$ were female and $43.6 \%$ were males.

Around $48.4 \%$ of cases for IOL implantation were having immature senile cataract (Figure 3).

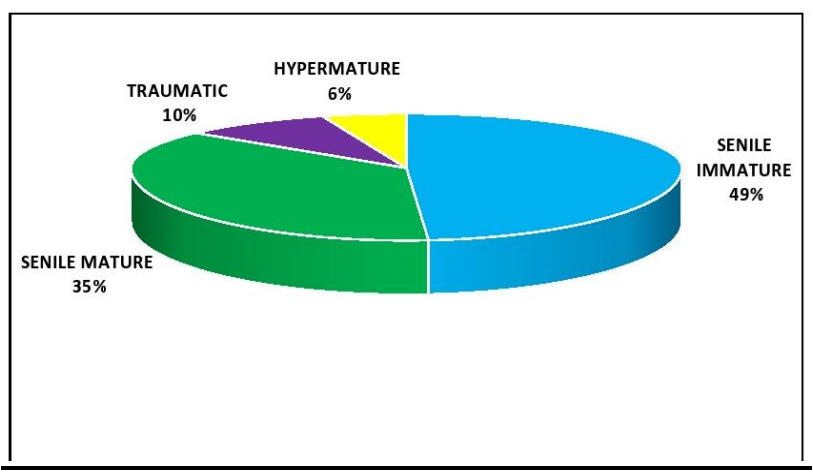

Figure 3: Most common indication shows $48.4 \%$ of cases for IOL implantation were having immature senile cataract.

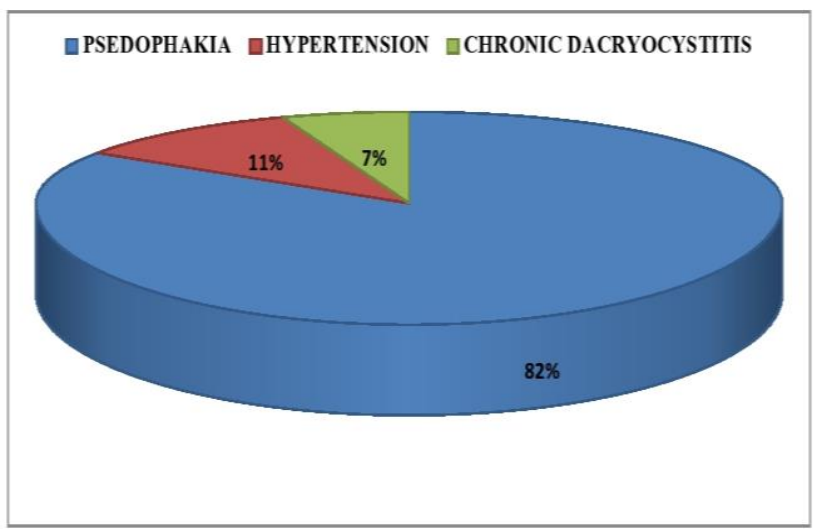

Figure 4: Cataract is most commonly associated with other condition like pseudophakia in the other eye in approx $45.2 \%$, cases.

We also find that approx $13.5 \%$ cases were bilateral affecting both the eyes. Cataract is also associated with other condition like pseudophakia in the other eye in approx $45.2 \%$, cases, metabolic disease like hypertension in $5.8 \%$ cases and chronic dacryocystitis in $3.9 \%$ cases (Figure 4).

Most commonly preferred route of administration is topical eye drops followed by oral route in preoperative cases and also after discharge but parenteral route followed by oral route is preferred in immediate postoperative period during hospital stay. Overall topical eye drops are most commonly used account for $46.9 \%$ cases followed by oral route in $40.8 \%$ cases, Figure 7 and Table 1.

Table 1: Commonly used route of administration.

\begin{tabular}{|llllll|}
\hline & $\begin{array}{l}\text { Total } \\
\text { no. of }\end{array}$ & $\begin{array}{l}\text { Topical } \\
\text { drugs }\end{array}$ & $\begin{array}{l}\text { eye drop } \\
(\%)\end{array}$ & $\begin{array}{l}\text { Oral } \\
(\%)\end{array}$ & $\begin{array}{l}\text { Parenteral } \\
(\%)\end{array}$ \\
\hline $\begin{array}{l}\text { Pre } \\
\text { operative }\end{array}$ & 570 & $\begin{array}{l}321 \\
(56.3 \%)\end{array}$ & $\begin{array}{l}249 \\
(43.7 \%)\end{array}$ & \\
\hline $\begin{array}{l}\text { Post } \\
\text { Operative }\end{array}$ & 345 & & $\begin{array}{l}162 \\
(47 \%)\end{array}$ & $183(53 \%)$ \\
\hline $\begin{array}{l}\text { On } \\
\text { discharge }\end{array}$ & 564 & $372(66 \%)$ & $\begin{array}{l}192 \\
(34 \%)\end{array}$ & \\
\hline Overall & 1479 & $\begin{array}{l}693 \\
(46.9 \%)\end{array}$ & $\begin{array}{l}603 \\
(40.8 \%)\end{array}$ & $\begin{array}{l}183 \\
(12.4 \%)\end{array}$ \\
\hline
\end{tabular}

Overall 564 drugs were prescribed on discharge in 156 prescriptions; So on an average 3.6 drugs were prescribed per prescription on discharge.

In a clear majority of patients amounting to $53.08 \%$, 4-5 drugs were employed after discharge while in almost every patient 3-4 drugs were employed preoperatively and 2-3 drugs were employed post operatively (Figure 6).

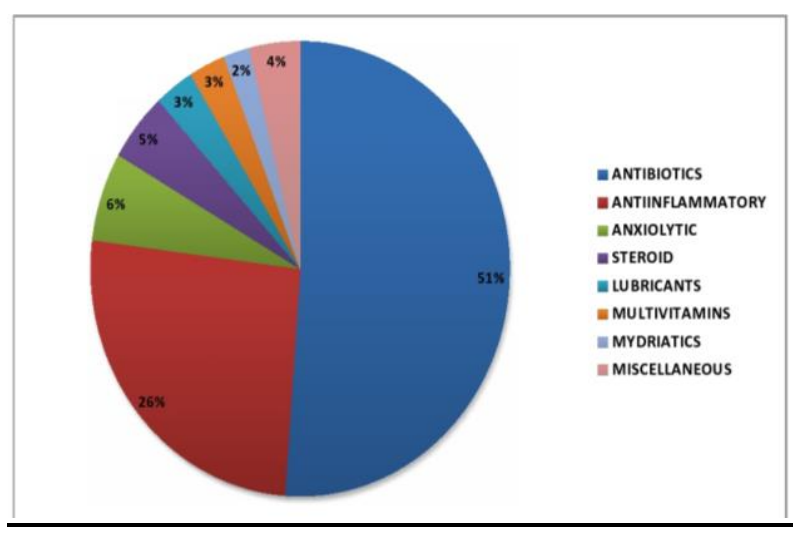

Figure 5: Overall most common group of drugs used preoprative, postoperative and on discharge are the antimicrobials followed by anti-inflammatory, anxiolytic, steroids, lubricants, mydriatics etc.

Generic name is used only in about $25 \%$ cases whereas in rest of the prescriptions brand name were used and fixed dose combination like gatifloxacin-dexamethasone/ 
prednisolone combination, moxifloxacindexamethasone/difludrenate combination were used.

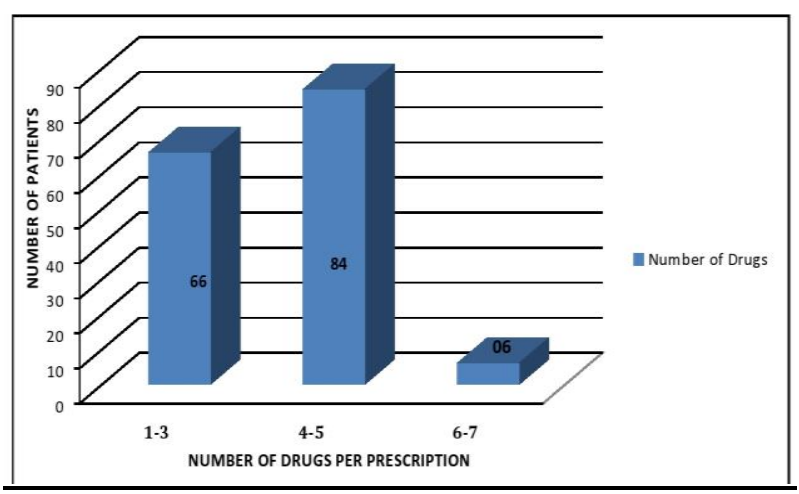

Figure 6: In a clear majority of patients amounting to $53.08 \%, 4-5$ drugs were employed after discharge. Overall 564 drugs were prescribed on discharge in 156 prescriptions; So on an average 3.6 drugs were prescribed per prescription on discharge.

Overall most common group of drugs used preoprative, postoperative and on discharge are the antimicrobials followed by anti-inflammatory, anxiolytic, steroids, lubricants, mydriatics etc (Figure 5). List of commonly used drugs and miscellaneous group is given in (Table 2).

Table 2: List of all drugs employed in patients undergoing cataract surgery.

\begin{tabular}{|c|c|c|}
\hline Topical eye drop & Oral & Parenteral \\
\hline \multicolumn{3}{|c|}{ Commonly used drugs } \\
\hline Flubiprofen & Ofloxacin & Diclofenac \\
\hline Gatifloxacin & \multicolumn{2}{|r|}{ Dexamethasone } \\
\hline Moxifloxacin & \multicolumn{2}{|l|}{ Alprazolam } \\
\hline $\begin{array}{l}\text { Gatifloxacin- } \\
\text { dexamethasone/ } \\
\text { Difludrenate / } \\
\text { prednisolone }\end{array}$ & \multicolumn{2}{|l|}{ Antioxidant } \\
\hline \multicolumn{3}{|l|}{$\begin{array}{l}\text { Moxifloxacin- } \\
\text { dexamethasone/ } \\
\text { Difludrenate }\end{array}$} \\
\hline \multicolumn{3}{|l|}{$\begin{array}{l}\text { Tropicamide/cycl } \\
\text { opentolate }\end{array}$} \\
\hline \multicolumn{3}{|l|}{ Lubricant(CMC) } \\
\hline \multicolumn{3}{|l|}{ Prednisolone } \\
\hline \multicolumn{3}{|l|}{$\begin{array}{l}\text { Sodium chloride } \\
\text { solution }\end{array}$} \\
\hline \multicolumn{3}{|c|}{ Miscellaneous drugs } \\
\hline \multicolumn{2}{|l|}{ Drugs } & No. of drugs $(\%)$ \\
\hline \multicolumn{2}{|c|}{$\begin{array}{l}\text { Amoxicillin/Paracetamol/Rabepr } \\
\text { azole or Antacid gel }\end{array}$} & $3.8 \%$ (each drug) \\
\hline \multicolumn{2}{|c|}{$\begin{array}{l}\text { Tobramycin/Timolol/Atropine/B } \\
\text { otropose }\end{array}$} & $1.9 \%$ (each drug) \\
\hline
\end{tabular}

Our study stated that Gatifloxacin eyedrop is the most frequently prescribed anti-microbial followed by oral ciprofloxacin pre-operatively for IOL implantation.
Flubiprofen eyedrop was prescribed as an antiinflammatory almost in $92.3 \%$ cases while $59.6 \%$ cases were prescribed alprazolam to relieve anxiety (Table 3 ).

Table 3: Pre-operative drugs employed in patients undergoing cataract surgery.

\begin{tabular}{|lll|}
\hline Oral drugs & Number of patients & Percentage \\
\hline Alprazolam & 93 & $59.6 \%$ \\
\hline Ciprofloxacin & 87 & $55.8 \%$ \\
\hline Ofloxacin & 66 & $42.3 \%$ \\
\hline Botrostat & 3 & $1.9 \%$ \\
\hline Amoxyclav & 3 & $1.9 \%$ \\
\hline Prednisolone & 3 & $1.9 \%$ \\
\hline Eye drops & Number of patients & Percentage \\
\hline Flubiprofen & 144 & $92.3 \%$ \\
\hline Gatifloxacin & 93 & $59.6 \%$ \\
\hline Moxifloxacin & 60 & $38.5 \%$ \\
\hline Atropin & 6 & $3.8 \%$ \\
\hline Tobramycin & 3 & $1.9 \%$ \\
\hline Timolol & 3 & $1.9 \%$ \\
\hline
\end{tabular}

Also, oral ciprofloxacin is the most frequently prescribed anti-microbial followed by oral ofloxacin postoperatively for IOL implantation. Injection Diclofenac was the most commonly used medication postoperatively and is given in $90.4 \%$ cases. Parenteral dexamethasone was the preferred glucocorticoid and was employed as an anti-inflammatory agent in nearly $30.8 \%$ of the cases (Table 4).

Table 4: Post-operative drugs employed in patients undergoing cataract surgery.

\begin{tabular}{|c|c|c|}
\hline $\begin{array}{l}\text { Parenteral } \\
\text { drugs }\end{array}$ & Number of patients & Percentage \\
\hline Diclofenac & 141 & $90.4 \%$ \\
\hline Dexamethasone & 48 & $30.8 \%$ \\
\hline Botropase & 3 & $1.9 \%$ \\
\hline Oral drugs & Number of patients & Percentage \\
\hline Ciprofloxacin & 69 & $44.2 \%$ \\
\hline Ofloxacin & 63 & $40.4 \%$ \\
\hline Amoxyclav & 6 & $3.8 \%$ \\
\hline Paracetamol & 6 & $3.8 \%$ \\
\hline Ibuprofen & 3 & $1.9 \%$ \\
\hline Prednisolone & 3 & $1.9 \%$ \\
\hline $\begin{array}{l}\text { Rabeprazole/ } \\
\text { Antacid gel }\end{array}$ & 6 & $3.8 \%$ \\
\hline
\end{tabular}

Antimicrobials are the most common group of drug employed on discharge followed by anti-inflammatory $(57.7 \%)$, lubricants $(28.9 \%)$, antioxidants multivitamin (26.9\%), mydriatics $(21.2 \%)$ and steroid eye drops $(9.6 \%)$. Out of antimicrobials oral ofloxacin (48.1\%) followed by gatifloxacin-dexamethasone eye drop $(36.5 \%)$ were prescribed (Table 5). 
Table 5: Drugs employed after discharge in patients undergoing cataract surgery.

\begin{tabular}{|lll|}
\hline Eye drops & Number of patients & Percentage \\
\hline $\begin{array}{l}\text { Gatifloxacin- } \\
\text { dexamethasone }\end{array}$ & 57 & $36.5 \%$ \\
\hline $\begin{array}{l}\text { Moxifloxacin- } \\
\text { difludrenate }\end{array}$ & 36 & $23.1 \%$ \\
\hline $\begin{array}{l}\text { Gatifloxacin- } \\
\text { prednisolone }\end{array}$ & 21 & $13.5 \%$ \\
\hline Gatifloxacin & 18 & $11.5 \%$ \\
\hline $\begin{array}{l}\text { Moxifloxacin- } \\
\text { dexamethasone }\end{array}$ & 15 & $9.6 \%$ \\
\hline Moxifloxacin & 6 & $3.8 \%$ \\
\hline $\begin{array}{l}\text { Gatifloxacin- } \\
\text { difludrenate }\end{array}$ & 3 & $1.9 \%$ \\
\hline Lubricant(cmc) & 45 & $28.9 \%$ \\
\hline Cyclopentolate & 24 & $15.4 \%$ \\
\hline Tropicamide & 9 & $5.8 \%$ \\
\hline Prednisolone & 15 & $9.6 \%$ \\
\hline $\begin{array}{l}\text { Sodium chloride } \\
\text { solution }\end{array}$ & 12 & $7.7 \%$ \\
\hline Oral drugs & Number of patients & Percentage \\
\hline Ofloxacin & 75 & $48.1 \%$ \\
\hline Ciprofloxacin & 69 & $44.2 \%$ \\
\hline $\begin{array}{l}\text { Antioxidant- } \\
\text { multivitamin }\end{array}$ & 42 & $26.9 \%$ \\
\hline Prednisolone & 6 & $3.8 \%$ \\
\hline $\begin{array}{l}\text { Pantoprazole/A } \\
\text { ntacid gel }\end{array}$ & 3 & $1.9 \%$ \\
\hline Atropin & 3 & $1.9 \%$ \\
\hline & 15 & \\
\hline
\end{tabular}

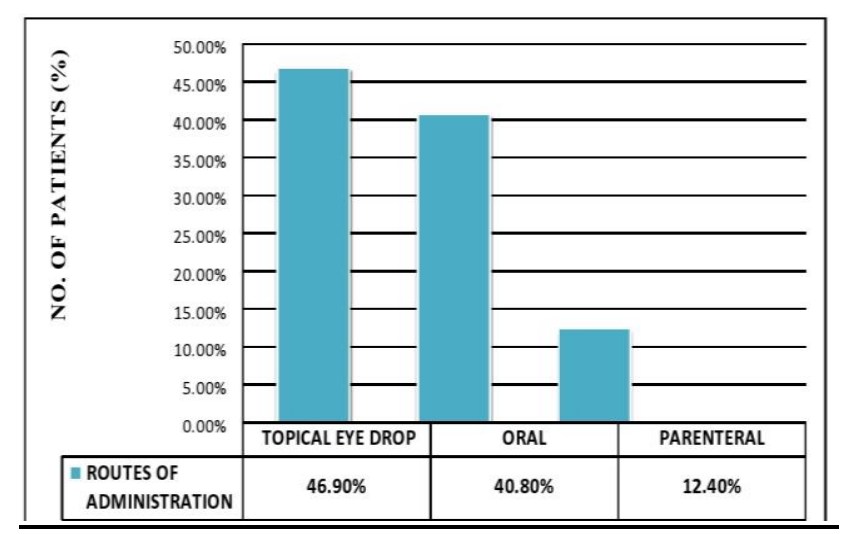

Figure 7: Most common route of administration shows overall topical eye drops are most commonly used account for $\mathbf{4 6 . 9 \%}$ cases followed by oral route in $40.8 \%$ cases.

\section{DISCUSSION}

The aim of the study was to draw attention towards certain issues like the drug utilization pattern, to find out irrationality amongst the prescriptions and to suggest methods for rationalization of existing therapeutic modalities. As we all know Cataract is a leading cause of blindness worldwide, and India alone has an estimated 8 million people who are blind due to cataract with an annual increase of approx 3 million. Surgical Intraocular Lens implantation is the best treatment along with a large number of currently available medications in the market to prevent post operative complications. ${ }^{13}$ But the surgeons need to have the appropriate knowledge about various drugs so that the best possible drug by best possible route in the right dose with the maximum efficacy and the minimum adverse effects can be selected for treatment.

As most of the patients visit this centre, results from this area may reflect the prescribing pattern of whole state. The study was done over a period of 6 months, from 1002-2015 to 10-08-2015 involving a total of 156 patients posted for cataract surgery.

The results of our study indicated that the maximum numbers of patients were encountered in the age group of 45-65 years which shows cataract is a fairly common ailment in the elderly.

Also females were more prone for the development of cataract than males. Most common indication for IOL implantation surgery in the present study was for senile immature cataract which was commonly associated with other condition like pseudophakia in the other eye, metabolic disease like hypertension and chronic dacryocystitis. Most commonly preferred route of administration was topical eye drops to prevent systemic side effects.

Drug prescriptions form an important point of contact between the health care provider and the user. Drug use indicators like average number of drugs used per prescriptions, number of generics are important for prescription audit. Generic name was used only in about $25 \%$ cases whereas in rest of the prescriptions brand name were used and fixed dose combination like gatifloxacin-dexamethasone/ prednisolone combination, moxifloxacin-dexamethasone/difludrenate combination were used. However duration of treatment, dosage and frequency were properly mentioned in all the prescriptions. Overall 564 drugs were prescribed on discharge in 156 prescriptions; So on an average 3.6 drugs were prescribed per prescription which is less than a study where it was above $7 .{ }^{14}$ In a clear majority of patients 4-5 drugs were employed after discharge. So it is preferable to keep the number of drugs per prescription as low as possible to prevent drug interaction, adverse effects and antibiotic resistance.

Our present study found out that all 156 patients studied were prescribed with both topical and oral antimicrobials. These were employed pre, post-operatively and after discharge. Overall most common group of drugs used preoprative, postoperative and on discharge are the antimicrobials followed by anti-inflammatory, anxiolytic, steroids, lubricants, mydriatics etc. 
Our study stated that Gatifloxacin eyedrop is the most frequently prescribed anti-microbial followed by oral ciprofloxacin pre-operatively for IOL implantation. Older drugs like Gentamicin $0.3 \%$ have been losing favour amongst clinicians owing to its side effect profile. ${ }^{15}$ So it shows that fluoroquinolones were the most commonly used antimicrobials. Flubiprofen eyedrop was prescribed as an anti-inflammatory almost in $92.3 \%$ cases while $59.6 \%$ cases were prescribed alprazolam to relieve anxiety.

Also, oral ciprofloxacin is the most frequently prescribed anti-microbial followed by oral ofloxacin postoperatively for IOL implantation to prevent post operative infection. Anti-inflammatory agents and steroids were the mainstay for decreasing post operative inflammation. Injection Diclofenac was the most commonly used medication postoperatively and is given in $90.4 \%$ cases. Parenteral dexamethasone was the preferred glucocorticoid and was employed as an antiinflammatory agent in nearly $30.8 \%$ of the cases.

After cataract surgery patient need prophylaxis against infections, inflammations, irritation, high ocular pressure to prevent long term complications for which antimicrobials are the most common group of drug employed on discharge followed by anti-inflammatory (57.7\%), lubricants $(28.9 \%)$, antioxidants multivitamin (26.9\%), mydriatics (21.2\%) and steroid eye drops (9.6\%).Out of antimicrobials oral ofloxacin (48.1\%) followed by gatifloxacin-dexamethasone eye drop $(36.5 \%)$ were prescribed. Lubricants were given to prevent irritation as continuous irritation can cause inflammation. ${ }^{16}$ Topical Steroids were prescribed to prevent postoperative anterior segment inflammation. ${ }^{17}$ Anti-inflammatory were prescribed to prevent macular edema after cataract surgery. ${ }^{18}$

So to conclude with keeping in considerations the objectives of this study, on evaluation of prescription pattern we found that antimicrobials were the most frequently used drugs both pre and post operatively and on discharge also followed by anti-inflammatory drugs. Among antimicrobials overall gatifloxacin eye drops and oral ciprofloxacin were most commonly prescribed.

Regarding the utilization of drugs per prescription it was found that even multiple antimicrobials are prescribed per prescription both as eye drops and oral preparations and in combination with steroids also and there is high rate of polypharmacy prevailing in all prescriptions to avoid post operative complications.

So various measures for rational prescription can be use of broad spectrum antimicrobials instead of multiple antimicrobials per prescription. Also systemic use of steroids post operatively should be kept at minimum so as to prevent delay wound healing. Our study also showed a significant awareness to avoid polypharmacy by keeping average number of drugs per prescription as low as possible to avoid increased cost of the therapy, therapeutic failure, adverse drug reactions, drug-drug interactions and for better patient compliance. Hence to promote rational prescribing it is essential to conduct drug utilisation studies, educating and training the doctors adequately regarding the need for rational prescribing.

\section{ACKNOWLEDGEMENTS}

At the very outset, we offer our prayers to the Almighty and our parents whose blessings will guide us on the path of wisdom and success. We take this opportunity to express our deep sense of respect and gratitude towards Dr. A. K. Adhikari, Principal-cum-Chief Superintendent, Gauhati Medical College and Hospital for being kind enough to allow us to carry out this study and for providing the necessary infrastructure to complete this work. We would like to express our sincere gratitude towards Prof. (Mrs.) Mangala Lahkar, Professor and Head, Department of Pharmacology, GMCH for guiding us throughout, with her valuable suggestions.

\section{Funding: No funding sources}

Conflict of interest: None declared

Ethical approval: The study was approved by the Institutional Human Ethical Committee

\section{REFERENCES}

1. Longo DL, Fauci AS, Kasper DL, Hauser SL, Jameson JL, Loscalzo. Harrison's principles of internal medicine. New York: Mcgraw-Hill; 2012:4022-55.

2. Bhavikkumar HS, Bhavin V, Divyesh JV, Jasmina SS. Drug Utilization Study in Cataract Patients from South Gujarat Region. Indian Journal of Pharmacy Practice. 2011;4(3):46.

3. Chang, David F. Antibiotic prophylaxis of postoperative endophthalmitis after cataract surgery: results of the 2014 ASCRS member survey. Journal of Cataract and Refractive Surgery. 2015;41(6):13005 .

4. Shah GK, Stein JD, Sharma S. Visual outcomes following the use of intravitreal steroids in the treatment of postoperative endophthalmitis. Ophthalmology. 2000;107(3):486-89.

5. Nikeghbali A, Falavarjani KG, Kheirkhah A. Pupil dilation with intracameral lidocaine during phacoemulsification. Journal of Cataract and Refractive Surgery. 2007;33(1):101-3.

6. Shiva F, Eidikhani AL, Padyab M. Prescription practices in acute pediatric infections. Journal of Pediatric Infectious Diseases. 2006;1(1):25-8.

7. Peuskens J. The evolving definition of treatment resistance. Journal of Clinical Psychiatry; 1999.

8. Aronson JK. Medication errors: what they are, how they happen, and how to avoid them. QJM. 2009;102(8):513-21.

9. McDowell SE, Ferner HS, Ferner RE. The pathophysiology of medication errors: how and 
where they arise. British Journal of Clinical Pharmacology. 2009;67(6):605-13.

10. Tully MP, Ashcroft DM, Dornan T. The causes of and factors associated with prescribing errors in hospital inpatients. Drug Safety. 2009;32(10):819-36.

11. Mahar, Michael L. Prescription order packaging system and method. U.S. Patent 6,769,228, issued August 3; 2004.

12. Hogerzeil HV. Promoting rational prescribing: an international perspective. British journal of clinical pharmacology.1995;39(1):1-6.

13. Javitt JC, Steinert RF. Cataract extraction with multifocal intraocular lens implantation: a multinational clinical trial evaluating clinical, functional, and quality-of-life outcomes. Ophthalmology. 2000;107(11):2040-8.

14. Binjawadgi A, Kakkeri RH, Patil BV, Dass P, Raikar S. Drug prescribing pattern in cataract surgery by intra -ocular lens implantation. Journal of Evolution of Medical and Dental Sciences. 2013;35(2):6723-32.

15. Liesegang TJ. Use of antimicrobials to prevent postoperative infection in patients with cataracts.
Current opinion in Ophthalmology. 2001;12(1):6874.

16. National eye institute (USA). Facts about Cataract. Maryland: National institute Of Health; 2010[cited 2010 Aug 30]. Available from: URL: http://www.nei.nih.gov/health/cataract/cataract_facts. asp.

17. Moroi SE, Lichter PR. Ocular pharmacology. In: Alfred Goodman and Gilman. The Pharmacological Basis of Therapeutics. $9^{\text {th }}$ edition, section XVI, New York: Mcgraw-Hill; 1996.

18. Reddy MS, Suneetha N, Thomas RK, Battu RR. Topical diclofenac sodium for treatment of postoperative inflammation in cataract surgery. Indian j Opthalmol. 2000;48(3):223-6.

Cite this article as: Adhikari $\mathrm{K}$, Bezbaruah BK.

Assessment of prescription pattern of cataract patients in the ophthalmology department at a tertiary health care institution. Int $\mathbf{J}$ Basic Clin Pharmacol 2017;6:653-9. 